many natives in it already, and that any further concession in their interest would be undoubtedly unpopular." As a matter of fact, it is a very high average if two Indians get in perhaps in a total of between 14 and 20 . At each competition the Government do their best to exclude them by holding examinations in London. Notwithstanding this Indians risk the perils of the deep, leave their hearth and home, and everything that is near and dear to them, to spend a number of years in an inhospitable climate, and spend a large sum of money on the offchance of succeeding in a proverbially uncertain competition, and that, too, in a foreign language. Yet they are grudged the few places which they now hold. Imagine the Ohinese filling most of the hospital and service appointments in Great Britain. How would the people here like to be told that the few Englishmen who wrested some appointments from the Oelestials bad done something which was unpopular and that "any further concession in their interest would be unpopular"? No, Sirs ; the boot is on the other leg. If we are to make any complaint (which I do not make so long as a fair competitive examination is held in England and India) it is that there are too many Englishmen in the Indian Services. Your correspondent further says that the Indian degrees are "not to be compared to the British ones." Whose fault is it? No one has ever dared to say that the Indian intellect is a whit inferior to that of other nations. Therefore the fault must rest with those who mould that intellect. We want in India teachers to be recruited from all quarters, not, as is the present custom, to take them simply from the Indian Medical Service which thus enjoys a close monopoly. This system excludes some of the most brilliant amongst our profession who have no desire to go through an army medical examination. We can only appeal to fair-minded Englishmen to preserve the legitimate interest of an Englishman without robbing their Indian fellow citizens of their inalienable rights as judged by the chivalrous sense of British justice.

$$
\text { I am, Sirs, yours faithfully, }
$$

SARAT K. MUllick.

New Cavendish-street, Cavendish-square, $W$. April 6th, 1901.

\section{"THE ELIMINATION OF ARSENIC THROUGH THE HAIR."}

\section{To the Editors of THE LANCET.}

SIRS,-You published in THE LaNCET of April 6th, p. 1044, a letter from Dr. A. Dupré which refers to the possibility of arsenic obtaining entry into the hair through the medium of the perspiration emanating from the scalp. The fact that the experiments referred to in our article in THE LANCET of March 23rd, p. 854, were all made with recent hair, and the knowledge that our beer patients had ceased taking in arsenic for some little time previously to the samples being obtained, should be sufficient to show the unlikelihood of the hair being contaminated in this way. We may further point out, however, that the hair of all the arsenical patients was regularly washed, and that particularly in the case of the patient taking the drug medicinally this occurred every day.

Dr. George Pernet, whose letter you publish in the same issue, does not, we fear, thoroughly grasp the scope of our article. We were very careful to point out that the affinity of arsenic for the skin and its appendages is common knowledge, and we certainly made no claim to have discovered the "fact that arsenic is stored up in the hair and nails." We confirm previous observations and go a step further. We clearly show that arsenic can not only be detected in the hair of people taking the drug, but that the quantity in any given sample can be estimated with perfect accuracy by the method indicated in our paper, and further demonstrate the use which this knowledge can be put to as an aid to the diagnosis of arsenical poisoning. It is necessary that Dr. Pernet should discriminate between the value for scientific purposes of an accurate estimation of the quantity of arsenic to be found in a weighed sample of hair and the mere detection of the drug in this appendage.

\section{We are, Sirs, yours faithfully,}

\section{"THE ROYAL ORTHOP ADIC HOSPITAL"}

\section{To the Editors of THE LANCET.}

SIRs, - I am surprised that the secretary-who as san official of the hospital should, I think I am justified in saying, be publicly neutral-has obtruded himself into this matter. I am, however, glad because it enables me to acknowledge an error of information of which I might otherwise not have been aware, as I asked at the railway station for a copy of THE LANCET and could not get one. The secretary and the assistant secretary will tell you that I have always desired to be most accurate in this question of site, but unfortunately, I presume, through having read the letter without glasses, I overlooked a nought-a very important thing in figures, I admit. I bave just re-read the letter and the word "sale" is not used, so I concluded that the offer was $£ 1200$ a year for leasing the Hanover-square part, as we have had several offers for leases. I readily apologise to you and all whom it may concern for that which everyone must see was a purely unintentional oversight. Obviously no one would desire to prejudice a good cause by purposely making incorrect statements. But this oversight in no way affects the real points at issue which are: (1) that $£ 37,700$ is considerably below the present value of the site; (2) that there is not the slightest necessity to part with our valuable property, which is increasing in value yearly as testified by experts; (3) that we are living rent free; (4) that partially building on our present site, even if we borrowed the money to do so, would increase the hospital's income $£ 500$ a year; and (5) that if it were necessary to do so we could rebuild the entire hospital on its present position, a magnificent one, for some $£ 12,000$, according to a letter which I read at the annual meeting in February last from a well-known firm of architects who have built another hospital. All these great advantages it is pro. posed to sacrifice for no sufficient reason which bas yet been furnished in order to enter on a career of very uncertain future and full of grave and totally unnecessary risks. In my judgment and that of other members of the committee and several governors this is not the cautious policy which should govern so very serious a matter as the moving of a long-established hospital and the selling of its only property.

About two years ago Sir J. W. Ellis valued the site at $£ 36,000$; about a year ago two experts valued its leasehold price at $£ 1500$ a year; and at the annual meeting last year I read a letter from a well known firm of valuers stating the then value of the site to be $£ 42,000$. Since that time the value of the site has enormously increased and will increase, as proved by the fact that two years ago only $£ 28,000$ were offered and now an offer of about $£ 10,000$ more is made and accepted so far as the majority of the committee is concerned. Some two years ago the adjoining property, which is only two feet wider, sold for between $£ 56.000$ to $£ 60000$, and shortly before that the property extending from Hanover-square to Oxford-street, facing that which is now being built on, fetched, I am informed, some $£ 65,000$ to $£ 70000$. In view of the enormous increase in value of property in this position I think anyone caring to inquire will find that the market value of our site is from $£ 45,000$ to $£ 50,000$, and to let some $£ 2000$ a year, and its real value much greater. But as there is not the slightest compulsion to sell, as $£ 2000$ have been spent in putting the hospital into thorough sinitary condition, as from the point of view of further enbancing the value of the hospital's property we should remain where we are and for several other mportant reasons, we have nothing to do with market value or the highest offer. Our duty clearly is to hold our piece of land and to increase our income by rebuilding the Oxfordstreet portion, or to leave well alone. I should add that though the choice of a proper site for a hospital is obviously a professional matter the views of the medical staff have been ignored, and though I have repeatedly given the committee credit for doing what they think to be best-though many believe them to be grierously mistaken-they have never even hinted that $I$ and those who agree with me have the best interests of the hospital at heart. I have been and am fighting a very difficult battle against rich men and as a consequence have made many enemies, but $I$ am conscious that $I$ am doing that which can be shown to be best for the hospital. I have had valuable advice from experts in accounts and in building operations and valuations, and until the argnments which I have adduced can be controverted-and hitherto 